\begin{tabular}{|c|l|}
\hline Title & Cloning and characterization of an odorant receptor in five Pacific sal mon \\
\hline Author(s) & Morinishi, Fumi; Shiga, Takumi; Suzuki, Norio; Ueda, Hiroshi \\
\hline Citation & $\begin{array}{l}\text { Comparative Biochemistry and Physiology. Part B, Biochemistry and Molecular Biology, 148(3), 329-336 } \\
\text { https://doi.org/10.1016/.cbpb.2007.06.010 }\end{array}$ \\
\hline Issue Date & 2007-11 \\
\hline Doc URL & http://hdl.handle.net/2115/39877 \\
\hline Type & article (author version) \\
\hline File Information & ueda_CBPB148.pdf \\
\hline
\end{tabular}

Instructions for use 


\title{
Cloning and Characterization of an Odorant Receptor in Five Pacific Salmon
}

\author{
Fumi Morinishi $^{1,2}$, Takumi Shiga ${ }^{3}$, Norio Suzuki ${ }^{3}$ and Hiroshi Ueda ${ }^{1,2 *}$ \\ ${ }^{1}$ Division of Marine Environment and Resources, Graduate School of Fisheries Science, \\ Hokkaido University, Sapporo 060-0809, Japan, ${ }^{2}$ Laboratory of Aquatic Bioresources and \\ Ecosystem, Field Science Center for Northern Biosphere, Hokkaido University, Sapporo \\ 060-0809, and ${ }^{3}$ Division of Biological Sciences, Graduate School of Science, Hokkaido \\ University, Sapporo 060-0810, Japan.
}

The nucleotide sequence data reported in this paper have been submitted to the DDBJ, EMBL, and GenBank nucleotide sequence databases, and are available under accession number AB232550 for cDNA of LSSOR1, AB255033 for cDNA of PSOR1, AB255034 for cDNA of RTOR1, AB255035 for cDNA of CSOR1, AB255036 for cDNA of MSOR1.

*Corresponding author: Tel. +81-11-706-2598;

Fax. +81-11-706-2598.

E-mail: hueda@fsc.hokudai.ac.jp 


\section{ABSTRACT}

The olfactory system of fish is extremely important as it is able to recognize and distinguish a vast of odorous molecules that are involved in wide ranges of behaviors including reproduction, homing, kin recognition, feeding and predator avoidance; all of which are paramount for their survival. We cloned and characterized one type olfactory receptors (ORs) from five salmonids: lacustrine sockeye salmon (Oncorhynchus nerka), pink salmon (O. gorbuscha), chum salmon (O. keta), masu salmon (O. masou) and rainbow trout (O. mykiss). Lacustrine sockeye salmon olfactory receptor 1 (LSSOR1) showed high sequence homology to the OR subfamily, and was expressed only in the olfactory epithelium (as indicated by PCR amplified genomic DNA and cDNA). OR genes from the five salmonids examined all showed strong homology (96-99\%) to each other. Hypervariable regions, believed to be ligand-binding pockets, showed homologous completely matched amino acid sequences except for one amino acid in pink salmon olfactory receptor 1 (PSOR1), revealing that these ORs may be well conserved among salmon species. These results suggest that the isolated 5 salmonid ORs might play an important role in salmon life cycles.

Key words: odorant receptor, olfactory epithelium, olfactory hypothesis, salmonids 


\section{INTRODUCTION}

The olfactory system of vertebrates is capable of recognizing and discriminating a large

number of different odorants in the surrounding environment. These ligands differ between aquatic and terrestrial vertebrate animals because of the different physiochemical characteristics

of these two habitats. However, the structure and function of the vertebrate olfactory system shares many common characteristics regardless of this fact. The initial step in olfactory transduction occurs in the olfactory epithelium (OE), where odorant ligands bind to specific receptors, termed olfactory receptors (ORs), expressed in the olfactory neurons (Buck and Axel, 1991; Zhao and Firestein, 1999; Glusman et al., 2000).

The OR genes constitute a large multigene family in each species, and are estimated to be composed of 50-100 genes in fish and several hundred genes in mammals (Zhao and Firestein, 1999; Glusman et al., 2000, 2001; Zhang and Firestein, 2002). The coding region of ORs is approximately 1 kb long, lacks introns, and generates G-protein-coupled receptors (GPCRs) that exhibit rhodopsin-like structures (Buck and Axel, 1991). Conserved amino acid motifs of seven transmembrane proteins in the ORs are distinguishable from other receptors (Buck and Axel, 1991; Pilpel and Lancet, 1999). 
Fish ORs identified thus far have several characteristics in common, such as several conserved motifs, an N-linked glycosylation site, and conserved cysteine (Zhao and Firestein, 1999; Glusman et al., 2000; Zhang and Firestein, 2002; Liu et al., 2003). In addition, however, less conserved sequences (hypervariable regions) such as the three transmembrane domains (TMD; TMD 3, 4 and 5) exist, and have been presumed to play important roles in potential ligand-binding structures of ORs (Ngai et al., 1993b; Pilpel and Lancet, 1999; Liu et al., 2003). These three domains are also highly divergent among paralogous members of the same subfamily, (as shown for Japanese loach [Misgurnus anguillicaudatus] ORs), with TMD 5 appearing to be the most divergent among these three TMDs (Irie-Kushiyama et al., 2004).

The ORs represent the first component of odour perception and discrimination. Two major types of ORs have been identified on the basis of primary structure and expression patterns in mammals: main ORs (MORs: expressed in ciliated olfactory sensory neurons [OSNs]) and vomeronasal receptors (VNRs: expressed in microvillar vomeronasal sensory neurons [VSNs]). The MORs and VNRs are believed to be involved in the perception of environmental odours and pheromones (semiochemicals), respectively (Firestein, 2001) and both types possess seven TMD proteins expressed in their membrane (Mombaerts, 1999; Matsunami and Amrein, 2003). Fish 
have a single kind of olfactory organ, whereas terrestrial vertebrates possess a vomeronasal organ in addition to a main olfactory organ (Eisthen, 1992; Dulka, 1993).

Fish olfaction is involved in wide ranges of behaviors including reproduction, homing, kin recognition, feeding and predator avoidance; all of which are paramount for their survival (Liley, 1982; Olsen and Liley, 1993; Nevitt et al., 1994; Hara and Zhang, 1996). In anadromous salmonids, olfaction is essential for successful completion of the homing migration (Hasler and Scholz, 1983). Recently, electrophysiological studies have clearly shown that amino acids play an important role in the homing behavior of salmonid fish (Shoji et al., 2000).

Fish ORs have been identified in several teleost species. Although previous studies have suggested that salmon ORs in the peripheral olfactory epithelium play an important role in salmonid homing migration, only a few putative MOR genes in Atlantic salmon have been identified to date (Wickens et al., 2001; Dukes et al., 2004, 2006). In this study, we isolated OR genes from five salmonid species: lacustrine sockeye salmon (Oncorhynchus nerka), pink salmon (O. gorbuscha), chum salmon (O. keta), masu salmon (O. masou) and rainbow trout (O. mykiss), in an effort to examine both their molecular characteristics and phylogeny among these salmonid species. 


\section{MATERIALS AND METHODS}

\section{Sample collection}

One- and three-year-old lacustrine sockeye salmon, 3-year-old masu salmon and one-year-old rainbow trout were obtained from Toya Lake Station, Field Science Center for Northern Biosphere, Hokkaido University. Adult pink salmon and adult chum salmon were obtained in the Yuubetsu River and in the Ishikari Bay, respectively. Fish were killed by decapitation, and olfactory rosettes were immediately removed and frozen on dry ice. Brain, kidney, liver, retina, heart, intestine, muscle and gill from yearling sockeye salmon and testis from 3-year-old sockeye salmon were also sampled. All the samples were stored at $-80^{\circ} \mathrm{C}$ until the RNA extraction. Total RNA was isolated using ISOGEN (Nippongene, Toyama, Japan) following the manufacture's instructions.

2. Isolation and characterization of lacustrine sockeye salmon olfactory receptor1 (LSSOR1) sequences.

First strand cDNA synthesis was carried out using the Superscript ${ }^{\mathrm{TM}}$ II, RNase H- reverse transcriptase system (GIBCO BRL, Rockville, MD, USA) using degenerated primer. Two types of degenerated primers were used for the PCR amplifications (Yasuoka et al., 1999, 
Asano-Miyoshi et al., 2000, Irie-Kushiyama et al., 2004, Wickens et al., 2001), with nested

polymerase chain reaction (PCR) to amplify a 490 bp fragment from lacustrine sockeye salmon

olfactory mRNA. The following 'hot start' thermal cycling parameters were used; $95^{\circ} \mathrm{C}$ for 3 min and $80^{\circ} \mathrm{C}$ for 1 min (1 cycle); addition of TaKaRa Ex Taq (TaKaRa, Shiga, Japan); $95^{\circ} \mathrm{C}$ for $1 \mathrm{~min}, 55^{\circ} \mathrm{C}$ for $1 \mathrm{~min}$ and $72^{\circ} \mathrm{C}$ for $1 \mathrm{~min}(35$ cycles); followed by a final DNA extension of 72 ${ }^{\circ} \mathrm{C}$ for 10 min. An Oligotex (TaKaRa) was used to purify mRNA. 3' and 5' rapid amplification of cDNA ends (RACE) with gene-specific primers (5' RACE primer and 3' RACE primer; Table 1) based on the DNA sequence of the original PCR fragment, was carried out using

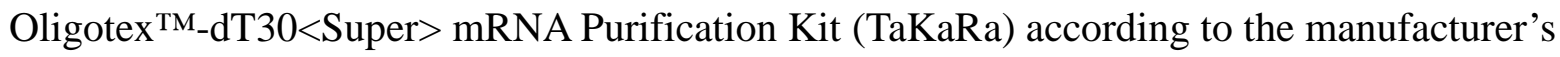
instructions.

All PCR products were analyzed by agarose gel (1\%) electrophoresis and cloned into the pGEM $^{\circledR}$-T easy vector (Promega, Tokyo, Japan). The purified DNA (GFX ${ }^{\mathrm{TM}}$ PCR DNA and Gel Band Purification Kit, Amersham Bioscience, Buckinghamshire, UK) was then cycle sequenced (PCR Thermal Cycler Dice; TaKaRa). The obtained DNA sequences were searched for in GenBank databases using the BLAST Sequence Analysis Tool (http://www.ncbi.nlm.nih.gov/BLAST/). 


\section{Expression of LSSOR1}

To verify patterns of expression among tissues, gene-specific primers (LSSOR1 complete primer) and $\beta$-actin primer (Table 1) were used to PCR amplify genomic DNA and cDNA from Table. 1 one-year-old lacustrine sockeye salmon $\mathrm{OE}$, brain, kidney, liver, retina, heart, intestine, muscle, gill and three-year-old lacustrine sockeye salmon testis. In addition, genomic DNA of yearling lacustrine sockeye salmon was prepared from the liver of male adult fishes by ISOTISSUE (Nippongene) following the manufacture's instructions. Several total RNAs were used in first strand cDNA synthesis after treated with DNase I to remove residual genomic DNA. Using the LSSOR1 primer, PCR was performed according to the following schedule: $95^{\circ} \mathrm{C}$ for $3 \min (1$ cycle), $94^{\circ} \mathrm{C}$ for $1 \mathrm{~min}, 55^{\circ} \mathrm{C}$ for $1 \mathrm{~min}$ and $72^{\circ} \mathrm{C}$ for $3 \mathrm{~min}$ (30 cycles); followed by a final DNA extension of $72^{\circ} \mathrm{C}$ for $10 \mathrm{~min}$. Using the $\beta$-actin primer, PCR was performed according to the following schedule: $95^{\circ} \mathrm{C}$ for $3 \min \left(1\right.$ cycle), $94^{\circ} \mathrm{C}$ for $1 \mathrm{~min}, 55^{\circ} \mathrm{C}$ for $1 \mathrm{~min}$ and $72^{\circ} \mathrm{C}$ for 1 min (30 cycles); followed by a final DNA extension of $72^{\circ} \mathrm{C}$ for $10 \mathrm{~min}$.

4. Isolation and characterization of salmonid fish OR sequences 
Double-strand OE cDNA from rainbow trout, masu salmon, pink salmon and chum salmon were carried out using the Superscript ${ }^{\mathrm{TM}}$ II, RNase H- reverse transcriptase system (GIBCO BRL) following the manufacture's instructions. LSSOR1 complete primers were used for the amplification of each putative salmonid ORs. PCR was performed according to the following schedule: $95^{\circ} \mathrm{C}$ for $3 \min \left(1\right.$ cycle), $94{ }^{\circ} \mathrm{C}$ for $1 \mathrm{~min}, 55{ }^{\circ} \mathrm{C}$ for 1 min and $72{ }^{\circ} \mathrm{C}$ for $3 \min (35$ cycles); followed by a final DNA extension of $72{ }^{\circ} \mathrm{C}$ for $10 \mathrm{~min}$.

All PCR products were cloned into the pGEM ${ }^{\circledR}$-T easy vector (Promega). The purified DNA (GFX ${ }^{\mathrm{TM}}$ PCR DNA and Gel Band Purification Kit, Amersham) was then cycle sequenced (PCR Thermal Cycler Dice; TaKaRa). The obtained DNA sequences were searched for in GenBank databases using the BLAST programme (http://www.ncbi.nlm.nih.gov/BLAST/).

Five salmonids of the OR amino acid sequences were aligned in ClustalW (http://www.ebi.ac.uk/clustalw/).

5. Phylogenetic analysis

In database searches, OR genes were picked up including catfish (Ngai et al., 1993a), goldfish (Cao et al., 1998), Atlantic salmon (Wickens et al., 2001), Japanese loach 
(Irie-Kushiyama et al., 2004) and zebrafish (Alioto et al., 2005). These amino acid sequence

data included various OR subfamilies, and were given temporary names following previous study

(Irie-Kushiyama et al., 2004).

Phylogenetic trees were depicted by NJ methods using GENETIX-WIN GENETIX

INFORMATION PROCESSING SOFTWARE (SOFTWARE DEVELOPMENT CO., LTD.,

Tokyo, Japan) with 1000 rounds of bootstrap analysis. 


\section{RESULTS}

1. Isolation and characterization of LSSOR1

Nested PCR with degenerated primers generated a 490 bp fragment showing strong sequence homology to previously published goldfish ORs (Cao et al., 1998). RACE PCR with gene-specific primers yielded 832 bp and 875 bp cDNA fragments (3' and 5' ends, respectively), both of which overlapped with the initial PCR fragment and displayed high sequence conservation with fish ORs. The three fragments, when assembled, produced a 2140 nucleotide (nt) cDNA sequence with putative open reading frame of $942 \mathrm{nt}$ encoding 314 amino acids (a.a.) and a stop codon (Fig. 1). The 5' untranslated region (UTR) and 3' UTR are 1-494 nt and 1436 $-2140 \mathrm{nt}$, respectively. The polyadenylation signal AATAAA is found at nt 2093, $40 \mathrm{nt}$ upstream of the polyadenylation site. A BLAST search revealed strongest amino acid sequence identity (Table 2 and Fig. 2) with previously published fish ORs; 69\% with goldfish subtype GFAs, GFA12 (GenBank accession No. $\underline{\text { AF083077) }}$ (Cao et al., 1998), 66\% with zebrafish Table. 2 Fig. 2

Protein 13.1 (GenBank accession No. $\underline{\text { AF012753) }}$ (Barth et al., 1997), 62\% with loach subtype D202 (GenBank accession No. AB115077) (Irie-Kushiyama et al., 2004), 59\% with catfish 202 (GenBank accession No. L L09220) (Ngai et al., 1993b). 


\section{Expression of LSSOR1}

LSSOR1 (GenBank accession No. $\underline{\mathbf{A B 2 3 2 5 5 0}}$ ) sequence was expressed only in the OE (Fig.

3). Amplification of $\beta$-actin from all tissues indicates successful isolation of RNA and synthesis

of cDNA. Differences in the size of PCR products between cDNA and genomic DNA (owing to

the presence of an intron in genomic DNA) demonstrated that the tissue samples were not contaminated by residual genomic DNA (Fig. 3).

3. Isolation and characterization of four salmonid fish OR sequences

Using LSSOR1 primers, we isolated four salmonids putative OR clones: chum salmon CSOR1 (GenBank accession No. $\underline{\text { AB255035), }}$, masu salmon MSOR1 (GenBank accession No.

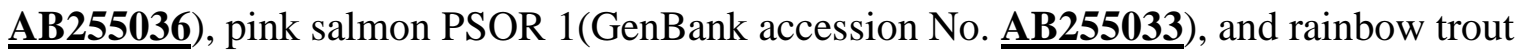
RTOR1 (GenBank accession No. $\underline{\text { AB255034) }}$ from the OE cDNA. All clones have 945 bp fragments showing strong sequence homology to LSSOR1. In common with other ORs, all salmonid ORs including LSSOR1 have a potential N-linked glycosylation site at position eight within the short extracellular N-terminal of the receptor sequence. The consensus 'Landmark' 
motifs that have been identified as unique to ORs in mammals (Zhao and Firestein, 1999) are also present (Figs. 2 and 4); these include mayDRyvAiCxPLxY motif at the N-terminal of the second Fig. 4 intracellular loop (positions 119-133 a.a.); KaFsTCxsh motif at the N-terminal of transmembrane domain $\dot{\text { sx }}$ (positions 237-245 a.a.); three cysteines in the second extracellular loop (positions 170, 180 and 190). Conserved cysteines 98 and 180 a.a. are believed to form a disulfide bridge between the first and second extracellular loops (Sharon et al., 1998). The NPxIY motif (positions 289-293) found in all GPCRs is present at the C-terminal of transmembrane domain seven (Gat et al., 1994; Fig. 4). A BLAST search revealed high homology amino acid sequence identity (Table 2).

Five salmonids ORs amino acid sequences show strong homology (96-99\%; Table 3), indicating that these ORs are well conserved among salmonids. Furthermore, the amino acid Table. 3 sequence of hypervariable regions TMD 3, 4 and 5, which were believed to be ligand-binding pockets, in five species matched completely except for one amino acid in PSOR1 (213 a.a.; Fig. 4).

4. Comparative analysis of orthologous subfamilies of salmonids and other fish species 
From GenBank databases, OR genes were picked up including catfish (Ngai et al., 1993a), goldfish (Cao et al., 1998), Atlantic salmon (Wickens et al., 2001), Japanese loach (Irie-Kushiyama et al., 2004) and zebrafish (Alioto et al., 2005). Six catfish ORs have previously been reported (Ngai et al., 1993a) and named as cf-32 (GenBank accession No.

L09219), cf-1 (GenBank accession No. L09217), cf-3 (GenBank accession No. L09218), cf-202 (GenBank accession No. L09220), cf-47 (GenBank accession No. L09221) and cf-8 (GenBank accession No. L09222). From the goldfish ORs, three OR genes have previously been reported (Cao et al., 1998) and named as gf-GFA2 (GenBank accession No. $\underline{\text { AF083076)}}$, gf-GFA12 (GenBank accession No. $\underline{\text { AF083077) }}$ and gf-GFA28 (GenBank accession No. $\underline{\text { AF083079)}}$. From the Atlantic salmon, single genes have been reported (Wickens et al., 2001) and named as as-ASOR1 (GenBank accession No. $\underline{\text { AY007188) }}$. From the Japanese loach ORs, four OR genes have previously been reported (Irie-Kushiyama, 2004) and named as jl-D32 (GenBank accession

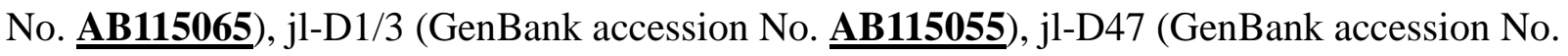

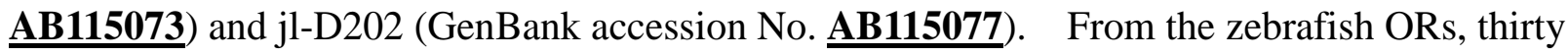
seven OR genes have previously been reported (Alioto et al., 2005) and named as zf-101 to zf-136. 
Thus, in total, 52 ORs have been identified from lacustrine sockeye salmon, Japanese loach, catfish, zebrafish, goldfish, and Atlantic salmon. We then aligned representatives of these 52

ORs, and generated the phylogenetic tree shown in Fig. 5. LSSOR1 was named in 202 subfamily

previously reported by Irie-Kushiyama et al. (2004).

Fig. 5 


\section{DISCUSSION}

The sense of olfaction is extremely important in fish. In anadromous salmonids, olfaction is essential for successful completion of the homing migration. The OR genes estimated to be composed of 50-100 genes in fish. However, much less is known about odorants and their receptors especially in salmonids.

In this study, one putative OR gene encoding a protein of 314 amino acids, LSSOR1, was isolated from lacustrine sockeye salmon. The Met, start codon, was at 1 a.a., and the stop codon was at 314 a.a., encoding a protein in the size range (300-350a.a.) of previously described for vertebrate ORs (Zhao and Firestein, 1999). Furthermore, this gene has a protein N-linked glycosylation site, as well as consensus 'Landmark’ motifs that have been identified as unique to ORs in mammals (Zhao and Firestein, 1999), and was expressed only in the olfactory epithelium of lacustrine sockeye salmon. There it is suggested that LSSOR1 is a new putative salmonid OR gene.

A BLAST search of LSSOR1 sequence revealed strong amino acid sequence identity with previously published fish ORs; 69\% with goldfish subtype GFAs categorized in MOR type,

GFA12 (GenBank accession No. $\underline{\text { AF083077) }}$ (Cao et al., 1998), 66\% with zebrafish Protein 13.1 
(GenBank accession No. AF012753) (Barth et al., 1997), 62\% with loach subtype D202

(GenBank accession No. AB115077) (Irie-Kushiyama et al., 2004), and 59\% with catfish 202

(GenBank accession No. L09220) (Ngai et al., 1993b). The LSSOR1 showed strong homology

to GFA12, categorized in MOR type, suggesting that LSSOR1 is also categorized in MOR type.

From our phylogenetic tree analysis, based on alignment of representatives of fish ORs,

LSSOR1 was categorized in the 202 subfamily. GFAs categorized in the 202 subfamily were

expressed in the olfactory epithelium, but not in brain, heart, liver and intestine of goldfish (Cao

et al., 1998), as was LSSOR1 in this study. GFAs are thought to be expressed in putative

ciliated cells in the olfactory epithelium suggesting that GFA receptors sense food odorants (Cao

et al., 1998). Though, ciliated olfactory receptor neurons can detect not only amino acid but

also bile salts (Hansen et al., 2003). Additionally, ciliated olfactory receptor neurons are

respond to a wide variety of odorants such as amino acids, urine, etiocholan-3 alpha-ol-17-one

glucuronide in rainbow trout (Sato and Suzuki, 2001). Since characterization of the odorant

ligand binding for these ORs should facilitate classification of the receptors, we should make a

characterization of these ligands immediately.

Four salmonid OR clones were isolated using LSSOR1 complete primer sets. As with 
LSSOR1, all clones encoded a protein of 314 amino acids (Met start codon at 1 a.a., stop codon was at 314 a.a.), had a protein N-linked glycosylation site, and consensus 'Landmark' motifs that have been identified as unique to ORs in mammals (Zhao and Firestein, 1999). Hypervariable regions in TMD 3, 4 and 5, which are believed to be ligand-binding pockets (Ngai et al., 1993b; Pilpel and Lancet, 1999; Liu et al., 2003), showed completely matched a.a. sequences except for one amino acid in PSOR1 (213 a.a.; see Fig. 4). It is suggested that these additional salmonid ORs may be binding the same odorants as LSSOR1 and that they are of the same functional type. In this study, LSSOR1 and the 4 salmonid OR amino acid sequences had very strong homology (96-99\%) to each other, suggesting that these ORs were well conserved among salmonids. It may be highly possible that 5 salmonid OR genes were functional genes conserved in salmonids. Based on the results of this study, it is suggested that the 5 salmonid ORs isolated play a crucial role in salmon life cycles.

Only one OR family was obtained in this study. The wealth of bioinformatic data of salmonids OR will help to define the functional genes that are reliable for survival, reproduction and homing. Additionally, LSSOR1 showed homology to GFAs that expressed ciliated cells in the olfactory epithelium (Cao et al., 1998). Though, ciliated olfactory receptor neurons can 
wide variety of odorants (Hansen et al., 2003; Sato and Suzuki, 2001). Therefore we can not conclude that LSSOR1 is completely amino acid receptor. Furthermore, the 5 ORs isolated in this study have not been shown to be functionally relevant via odorant ligand binding activity. Characterization of the odorant ligand binding for these ORs should facilitate classification of the receptors, and may allow the identification of the behaviours in which these receptors are involved. Further molecular biological studies on ORs are needed to enhance our understanding of important olfactory functions in salmonid species. 


\section{ACKNOWLEDGEMENTS}

We thank to Mr. Haruna, Toya Lake Station, for his help in maintenance of salmon used in

the present study, and also thank to Dr. Hugh E. Jarrard, Washington College, for critical reading

of the manuscript. This study was supported in part by Grant-in-Aid for Scientific Research

(A)(18208017) from the Japan Society for the promotion of Science, and a natural science grant

(35-4) from the Mitsubishi Foundation to HU. 


\section{REFERENCES}

Alioto, T. S. and Ngai, J., 2005. The odorant receptor repertoire of teleost fish BMC Genomics. $6,173$.

Asano-Miyoshi, M., Suda, T., Yasuoka, A., Osima, S., Yamashita, S., Abe, K., Emori, Y., 2000.

Random expression of main and vomeronasal olfactory receptor genes in immature and mature olfactory epithelia of Fugu rubripes. J. Biochem. 127, 915-924.

Barth, A.L., Dugas, J.C. and Ngai, J., 1997. Noncoordinate expression of odorant receptor genes tightly linked in the zebrafish genome. Neuron 19, 359-369.

Buck, L., Axel, R., 1991. A novel multigene family may encode odorant receptors: a molecular basis for odor recognition. Cell 65, 175-187.

Cao, Y., Oh, B.C., Stryer, L., 1998. Cloning and localisation of two multigene receptor families in goldfish olfactory epithelium. Proc. Natl. Acad. Sci. U. S. A. 95, 11987-11992.

Dukes, J.P., Deaville, R., Bruford, M.W., Youngson, A.F., Jordan, W.C., 2004. Odorant receptor gene expression changes during the parr-smolt transformation in Atlantic salmon. Mol. Ecol. 13, 2851-2857.

Dukes, J.P., Deaville, R., Gottelli, D., Neigel, J.E., Bruford, M.W., Jordan, W.C., 2006. Isolation 
and characterisation of main olfactory and vomeronasal receptor gene families from the Atlantic salmon (Salmo salar). Gene 371, 257-267.

Dulka, J.G., 1993. Sex pheromone systems in goldfish: comparisons to vomeronasal systems in tetrapods. Brain Behav. Evol. 42, 265-280.

Eisthen, H.L., 1992. Phylogeny of the vomeronasal system and of receptor cell types in the olfactory and vomeronasal epithelia of vertebrates. Microsc. Res. Tech. 23, 1-21.

Firestein, S., 2001. How the olfactory system makes sense of scents. Nature 413, 211-218.

Gat, U., Nekrasova, E., Lancet, D., Natochin, M., 1994. Olfactory receptor proteins: expression, characterisation and partial purification. Eur. J. Biochem. 225, 1157-1168.

Glusman, G., Bahar, A., Sharon, D., Pilpel, Y., White, J. Lancet, D., 2000. The olfactory receptor gene superfamily: data mining, classification, and nomenclature. Mamm. Genome 11, 1016-1023.

Glusman, G., Yanai, I., Rubin, I., Lancet, D., 2001. The complete human olfactory subgenome. Genome Res. 11, 685-702.

Hara, T.J., Zhang, C., 1996. Olfactory responses to putative pheromones and their neural pathways in salmonids. In: A.V.M. Canario and D.M. Power, Editors, Fish Pheromones: 
Origins and Modes of Action, University of Algarve, Faro, 82-97.

Hansen, A., Rolen, S.H., Anderson, K., Morita, Y., Caprio, J., Finger, T.M., 2003. Correlation between olfactory receptor cell type and function in the channel catfish. J. Neurosci. 23, 9328-9339.

Hasler, A.D., Scholz, A.T., 1983. Olfactory imprinting and homing in salmon: Investigations into the mechanism of the imprinting process. Springer-Verlag, Berlin, Heidelberg, New York, Tokyo, 134, 3-540-12519-1.

Irie-Kushiyama, S., Asano-Miyoshi, M., Suda, T., Abe, K., Emori, Y., 2004. Identification of 24 genes and two pseudogenes coding for olfactory receptors in Japanese loach, classified into four subfamilies: a putative evolutionary process for fish olfactory receptor genes by comprehensive phylogenetic analysis. Gene 325, 123-135.

Liley, N.R., 1982. Chemical communication in fish. Can. J. Fish. Aquat. Sci. 39, 22-35.

Liu, A.H., Zhang, X., Stolovinzky, G.A., Califano, A., Firestein, S.J., 2003. Motif-based construction of a functional map for mammalian olfactory receptors. Genomics 81, 443-456.

Matsunami, H., Amrein, H., 2003. Taste and pheromone perception in mammals and flies. 
Genome Biol. 4, 220.

Mombaerts, P., 1999. Molecular biology of odorant receptors in vertebrates. Annu. Rev. Neurosci. 22, 487-509.

Nevitt, G.A., Dittman, A.H., Quinn, T.P., Moody, W.J., 1994. Evidence for a peripheral olfactory memory in imprinted salmon. Proc. Natl. Acad. Sci. U. S. A. 91, 4288-4292.

Ngai, J., Chess, A., Dowling, M.M., Necles, N., Macagno, E.R., Axel, R., 1993b. Coding of olfactory information: topography of odorant receptor expression in the catfish olfactory epithelium. Cell 72, 667-680.

Ngai, J., Dowling, M.M., Buck, L., Axel, R., Chess, A., 1993a. The family of genes encoding odorant receptors in the channel catfish. Cell 72, 657-666.

Olsen, K.H., Liley, N.R., 1993. The significance of olfaction and social cues in milt availability, sexual hormone status and spawning behaviour of male rainbow trout (Oncorhynchus mykiss). Gen. Comp. Endocrinol. 89, 107-118.

Pilpel, Y., Lancet, D., 1999. The variable and conserved interfaces of modeled olfactory receptor proteins. Protein Sci. 8, 969-977.

Sato, K. and Suzuki, N., 2001. Whole-cell Response Characteristics of Ciliated and Microvillous 
Olfactory Receptor Neurons to Amino Acids, Pheromone Candidates and Urine in Rainbow Trout. Chem. Senses. 26, 1145-1156

Sharon, D., Glusman, G., Pilpel, Y., Horn-Saban, S., Lancet, D., 1998. Genome dynamics, evolution, and protein modelling in the olfactory receptor gene superfamily. Ann. N.Y. Acad. Sci. 855, 182-193.

Shoji, T., Ueda, H., Ohgami, T., Sakamoto, T., Katsuragi, Y., Yamauchi, K., Kurihara, K., 2000. Amino acids dissolved in stream water as possible home stream odorants for masu salmon. Chem. Senses. 25, 533-520.

Wickens, A., May, D., Rand-Weaver, M., 2001. Molecular characterisation of a putative Atlantic salmon (Salmo salar) odorant receptor. Comp. Biochem. Physiol. Part B 129, 653-660.

Yasuoka, A., Endo, K., Asano-Miyoshi, M., Abe, K., Emori, Y., 1999. Two subfamilies of olfactory receptor genes in medaka fish, Oryzias latipes: genomic organization and differential expression in olfactory epithelium. J. Biochem. 126, 866-873.

Zhang, X., Firestein, S., 2002. The olfactory receptor gene superfamily of the mouse. Nat. Neurosci. 5, 124-133.

Zhao, H., Firestein, S., 1999. Vertebrate odorant receptors. Cell. Mol. Life. Sci. 56, 647-659. 


\section{FIGURE LEGENDS}

Fig. 1. Nucleotide and amino acid sequence of lacustrine sockeye salmon odorant receptor1, LSSOR1 (GenBank accession number $\underline{\text { AB232550). }}$ The 5'-UTR and 3'-UTR are shown 1-494 nt and 1436-2140 nt, respectively. The coding region is shown 495-1435 nt. Putative amino acid sequence is described under the coding region. The Met (ATG) start codon is at $495 \mathrm{nt}$, and the stop codon (TAA, asterisk) is at $1433 \mathrm{nt}$. The polyadenylation signal AATAAA (2093 nt) and one potential N-linked glycosylation site (507-515 nt) are underlined. Shaded areas indicate the several motifs. Boxed areas indicate the conserved cysteines. Double lines indicate the predicted transmembrane domains (TMD).

Fig. 2. The amino acid sequence alignment of odorant receptors from lacustrine sockeye salmon (LSSOR1), goldfish (GFA12), zebrafish (zf13-1), Japanese loach (D202-1) and channel catfish (cf-202; references and accession numbers are given in the text). The multiple alignment is performed using GENETIX-WIN GENETIX INFORMATION PROCESSING SOFTWARE. Asterisks indicate identical amino acids. Bars indicate gaps inserted for optimal alignment. 
The Met start codon is at 1 a.a. and the stop codons are described as $<$ stop $>$. Shaded areas indicate the several motifs. Boxed areas indicate the conserved cysteines. Double lines indicate the predicted transmembrane domains (TMD).

Fig. 3. Results of $2 \%$ agarose gel electrophoresis of RT-PCR products from a variety of lacustrine sockeye salmon tissues using LSSOR1-specific primers. OE olfactory epithelium, B brain, $\mathrm{T}$ testis, $\mathrm{K}$ kidney, $\mathrm{L} \quad$ liver, $\mathrm{R}$ retina, $\mathrm{H}$ heart, $\mathrm{I}$ intestine, $\mathrm{M}$ muscle, Gi gill, $\mathrm{G}$ genomic DNA. Molecular weight (in kb) show at right.

Fig. 4. The amino acid sequence alignment of odorant receptors from five salmonids OR gene, lacustrine sockeye salmon (LSSOR1), chum salmon (CSOR1), pink salmon (PSOR1), masu salmon (MSOR1) and rainbow trout (RTOR1). The multiple alignment is performed using GENETIX-WIN GENETIX INFORMATION PROCESSING SOFTWARE. Asterisks indicate identical amino acids. The Met start codon is at 1 a.a. and the stop codons are described as $<$ stop $>$. Shaded areas indicate the several motifs. Boxed areas indicate the conserved cysteines. Double lines indicate the predicted transmembrane domains (TMD). The arrows indicate only 
one difference sequence in hypervariable regions (TMD 3, 4 and 5).

Fig. 5. Phylogenetic tree of odorant receptors from 15 fish OR genes. Catfish OR genes; cf-32A, cf-1, cf-3, cf-202, cf-47 and cf-8. Goldfish OR genes; gf-GFA2, gf-GFA12 and gf-GFA28. Atlantic salmon OR gene; as-ASOR1. Japanese loach OR genes; jl-D32-1, jl-D1/3-1, jl-D47-1 and jl-D202-1. Lacustrine sockeye salmon OR gene; LSSOR1. The tree was depicted by UPGMA methods using GENETIX-WIN GENETIX INFORMATION PROCESSING SOFTWARE. Gray bar indicates the clades of the 202 subfamily. 


\section{TABLES}

Table 1. Sequence of primers using in this study.

\begin{tabular}{lll}
\hline Primers & Primer Set $\left(5^{\prime} \rightarrow 3^{\prime}\right)$ \\
\hline$\beta$-actin primer & sense & 5' CGTCACCAACTGGGACGACA 3' \\
& antisense & 5' GCTCGTAGCTCTTCTCCAG 3' \\
5' RACE primer & outer & 5' TGGAGGGAGCAGGCTATACA 3' \\
& inner & 5' GGGTATCTGAGTGGGAAACA 3' \\
3' RACE primer & outer & 5' TGTTTCCCACTCAGATACC 3' \\
& inner & 5' CGGCATTAGATTCAGCACTG 3' \\
LSSOR1 complete primer & sense & 5' GCTGTCTCTACTAGACCATC 3' \\
& antisense & 5' GGCTTACAGCAAAGACATTCTCC 3'
\end{tabular}


Table 2. Percentage identity between ORs of various species and salmonids; lacustrine sockeye salmon (LSSOR1), chum salmon (CSOR1), pink salmon (PSOR1), masu salmon (MSOR1) and rainbow trout (RTOR1); amino acid sequences, aligned using the ClustalW.

\begin{tabular}{|c|c|c|c|c|c|}
\hline Species (clone) & LSSOR1 & CSOR1 & PSOR1 & MSOR1 & RTOR1 \\
\hline Goldfish (GFA12) & $69 \%$ & $69 \%$ & $70 \%$ & $69 \%$ & $70 \%$ \\
\hline Zebrafish (Protein 13.1) & $66 \%$ & $66 \%$ & $67 \%$ & $66 \%$ & $67 \%$ \\
\hline Loach (D202-1) & $62 \%$ & $62 \%$ & $62 \%$ & $61 \%$ & $63 \%$ \\
\hline Catfish (cf-202) & $59 \%$ & $59 \%$ & $59 \%$ & $58 \%$ & $59 \%$ \\
\hline \multicolumn{6}{|c|}{ 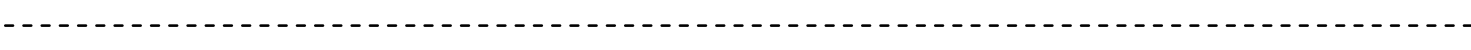 } \\
\hline Atlantic salmon (ASOR1) & $33 \%$ & $33 \%$ & $33 \%$ & $33 \%$ & $33 \%$ \\
\hline
\end{tabular}

Table 3. Percentage identity of 5 salmonids ORs amino acid sequences, lacustrine sockeye salmon (LSSOR1), chum salmon (CSOR1), pink salmon (PSOR1), masu salmon (MSOR1) and rainbow trout (RTOR1) aligned using the ClustalW

\begin{tabular}{|c|c|c|c|c|c|}
\hline Species (clone) & PSOR1 & CSOR1 & LSSOR1 & MSOR1 & RTOR1 \\
\hline PSOR1 & - & $99 \%$ & $99 \%$ & $97 \%$ & $97 \%$ \\
\hline CSOR1 & & - & $99 \%$ & $97 \%$ & $97 \%$ \\
\hline LSSOR1 & & & - & $97 \%$ & $97 \%$ \\
\hline MSOR1 & & & & - & $96 \%$ \\
\hline RTOR1 & & & & & - \\
\hline
\end{tabular}




\section{Fig. 1}

CGCGGATCCGAACA 14 CTGCGTTTGCTGGCTTTGATGAAAAGACATCAGATTTGATAAGTCCTTATTTACTTCTATGCAGATCAGGAGTTACATTGCATGCCTTAATCGCTCATGTTATGCATCTTTCTTGATGTG 134 TITTCTGAATATATTTTGAATCTGAATGTCATGGAATATGTTCTCTAATCTTTAGATGACAACATTGGATAACTTTAGTCCATTATACAAGACTCCATTGAAAGGCTTACTGTGAGGTGC 254 AGCTTTTGCATTGACATGCCCCACTATGGGGCGAAAATAGATTGTTCTCTGTGCGATTGCTGAATAACAGTCATTCATGATTTTTATTTGTATTCATTAATTGTCTTTATATCTTGAAAT 374 GAATATGAAGTGGGACATATAATGTGATCAATACTTTGGTATCATGTGTAATATCAATAAGATACTGTGATGTTAAAACATACCGGTACGTTAGGTTGCTGTCTCTACTAGACCATCATC 494

TMD1

ATGTCAGTGAGGAATCACAGCTTTGTGACGGAGTTTGTCATCGTTGGGTTCCCTGGACTTCAGCCAGAGTTCTACGGT $\overline{\text { CTTGCCTCTGCTGTATTATTGATTGTTTATTGTTGCACTTTA }}$ 614

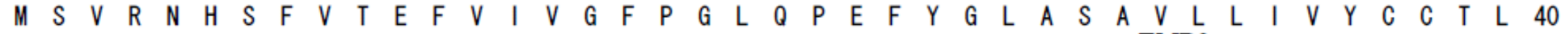
TMD2

$\overline{\overline{\text { ATAGGAAATTTTGCTGTTCTTATCTTGTTTGCAACTCCTAACATTCTCCATAAACCCATGTATATTATCATTTTGAATCTGGTTGTGTCTGACGTGCTATTCAGCACCACCACTTTACCA }}} \overline{\overline{\text { 734 }}}$

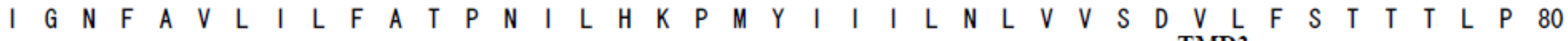

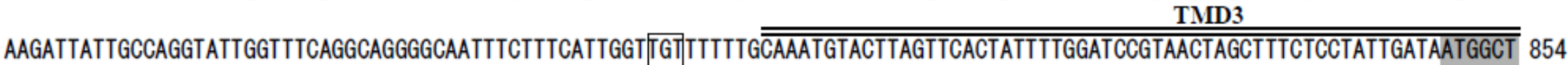

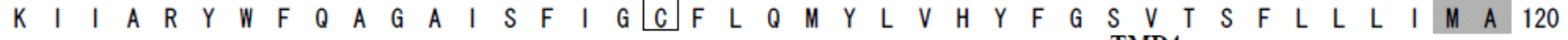

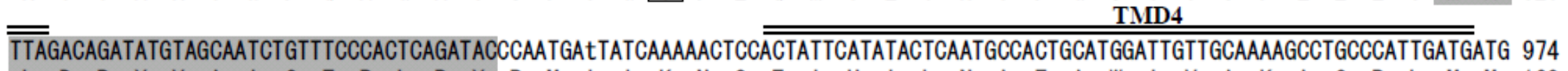

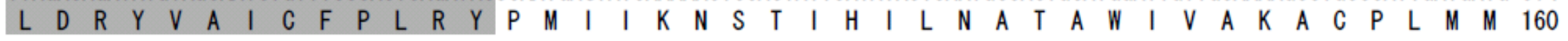

GTAATTAGGGCCTATCCTCTTCCTTACTGTGGACTCAAACACAATCTTGCAGTGCTTCIGTGATCATATTTCTATAACAAAGCTTGCA TGGACTGATAGAGCCCCTTATAGTTTTCCTGCT 1094

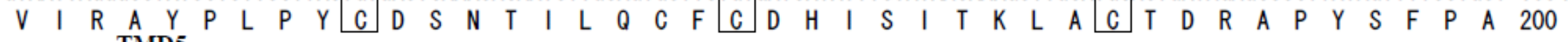
TMD5

$\overline{\overline{\text { TTTGTTACAGCAATGGTGGTATTACTGGGACCTCTCGTCTTTATTATATTCTCATATTGCTCTATTATTGTGGCAGTTGTTCAGATTGCGAGCCCCCAAGGCCGCCTCAAAACCCTTTCT }}}$ 1214

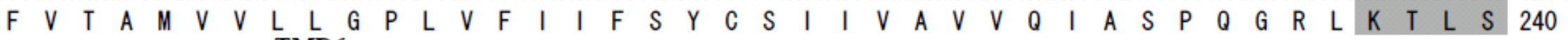
TMD6

$\overline{\text { ACCTGCAGTGGTCAGCTGATCATCATTGCCCTGTATTATCTCCCCAGGTGTTTTATTTATCTGGGCAGTAACGTCGGCATTAGATTCAGCACTGATTTACATATTGTTATTATCATGTTG }}$ 1334

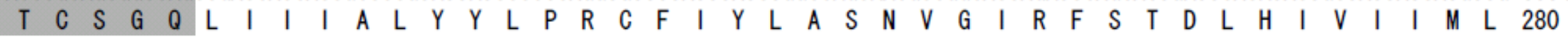
TMD7

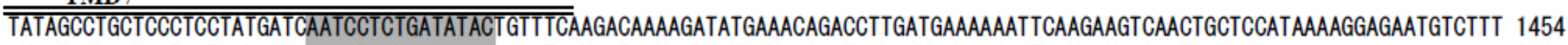

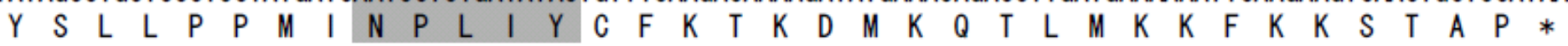

GCTGTAAGCCAATGCTTCAAATTATTTTTTTGTTCTGTTATCATGTTTAGAAATACTTGTCCCTACAAGAATACCAACTGAGTACCATATCCTAAATTGACATCCAAAATGGACATATAA 1574 AGGGAAAGGAAAGGGGGATACCTAGTCAGTTGCACAACTGAATGCCTTCAATTGAAATGTGTCTTCAGCATTTAACCCAACCCCTCTGAATCAGAGAGGGGCGGAGGGCTGCCTATATA 1634 AGGCCCTGCCTCTGTGTAGCAGTAGATAACGCCTTGTTAGATTGGCACAGATAGAGCATTTAGTGTTTATTGTTGGACAAAGATTATTATGTATTTAGTTATTTCAAATATAGTTGTTTC 1814 TGATATTGTCTTTAGGACAACCACATTACTCAAGATTATTGCCAGTTATAGCCAATGATTACATTTGTTTTGAATCAGTTTCTTTTATTAATTTCAGAAGTTCCTACAACAATATGAACT 1934 GATTACCAAACCCTACCTTGAAATCGAAACTTACATTCAGACCTTTAGAAAGTATACACACCCCTTTACGTTTTCCACACTTTGTCGTGTTACAACCATTATTATTTTTTTATTGTGGG 2054 GGGTGGTTCAGGAGTAAACATGTGCTTAACGAGTCACTTAATAAATCACATGGATTCACTCTGTGTGCAATAATAAAAAAAAAAA 
TMD1

LSSOR1 GFA12 zf13-1 D202-1 cf-202

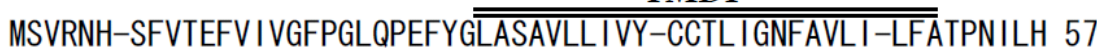
$*$ SSGNNS-FVKD $* \mathrm{~F} * \mathrm{~V} * * * * * Q \mathrm{PGYYGAVAA}-\mathrm{LLLFAYV} * \mid * \mathrm{~V} * * \mathrm{GIFIAL}-\mathrm{FTLEKR} * \mathrm{H} 57$ $*$ SAGN IS-FVKE*F*V*****QKGYFDSVAA-LMLFVFV*I*A**GTFLIL-FSLEKS*H 57 $*$ MSVGNVSF IKA $* I * V * * * * * Q P R Y Y G I V S A V L F F V Y-V * T * V * * A-V F I T L F V L S K T * \mathrm{~K} 58$ $*$ PEGN I TNV-KN*V*L *****PPNYYGLVSVVMFFVYV-*T*|**CTFFTLFLR-EKS*Q 57

\section{TMD2}

\section{TMD3}

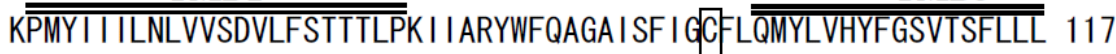
$* * \mathrm{M} * \mathrm{~N}|\mathrm{IL} * * \mathrm{VVS} * \mathrm{~L} * * * * * \mathrm{~T} * * * * * \mathrm{~S} * * \mathrm{~W} * \mathrm{Q} \mathrm{D} * \mathrm{~S} * * * \mathrm{~T} * * * *| * * \mathrm{YF} * * * * \mathrm{GS} * \mathrm{SS} \mathrm{V} \mid * \mathrm{~A} 117$ $* * \mathrm{M} * \mathrm{Y} \mathrm{V}|\mathrm{L} * * \mathrm{VAS} *| * * * * * \mathrm{~T} * * * * * \mathrm{~A} * * \mathrm{~L} * \mathrm{QD} * \mathrm{G} * * * \mathrm{M} * * * *|* * \mathrm{YF} * * * * \mathrm{GT} * \mathrm{NAF}| * \mathrm{~A} 117$ $* * \mathrm{~V} * \mathrm{YFIV} * * \mathrm{AVC} * \mathrm{~V} * * * * * \mathrm{~A} * * * * * \mathrm{~S} * * \mathrm{~W} * \mathrm{ED} * \mathrm{~S} * * * \mathrm{~L} * * * \mathrm{~L} * * \mathrm{FF} * * * * \mathrm{GT} * \mathrm{SSH} \mid * \mathrm{~A} 118$ $* * \mathrm{M} * \mathrm{Y}|\mathrm{ML} * * \mathrm{AAS} * \mathrm{~V} * * * * * \mathrm{~T} * * * * * \mathrm{~A} * * \mathrm{~W} * \mathrm{GD} * \mathrm{~S} * * * \mathrm{~V} * * * k| * * \mathrm{Q} \mathrm{F} * * * * \mathrm{AT} * \mathrm{NALV} * \mathrm{~A} 117$

\section{TMD4}

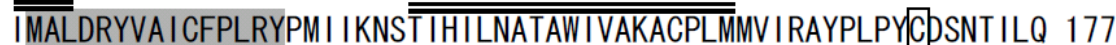
$|\mathrm{M} * \mathrm{~F} * * * * *| * \mathrm{~N} * \mathrm{~L} * * \mathrm{PN} * \mathrm{VTKLN}|\mathrm{FC} * \mathrm{CLAA} * \mathrm{VLTNTCP} * \mathrm{MMA} * * * \mathrm{YP} * * * * * S \mathrm{G} * *| \mathrm{I} \mid \mathrm{H} 177$ $|\mathrm{M} * \mathrm{~F} * * * * *| * \mathrm{~N} * \mathrm{~L} * * \mathrm{PN} * \mathrm{VTKWN}$ IFY*CLIS*VI ANVTP*MMV***YP*****AE**IIQ 177 $\mathrm{LL} *|* * * * *| * \mathrm{H} * \mathrm{~F} * * \mathrm{YS} * \mathrm{MTNKNVL}|* \mathrm{CCVA} * \mathrm{VLAYPGP} * \mathrm{ML}| * * * \mathrm{YP} * * * * A \mathrm{AE} * * \mid \mathrm{VH} 178$ $\mathrm{VM} * \mathrm{~F} * * * * * \mathrm{~V} * \mathrm{~N} * \mathrm{~L} * * \mathrm{VN} * \mathrm{VKEST}$ ILG*CVVS*LLAEPTV*TTV***TS*****AS**VIQ 177

\section{TMD5}

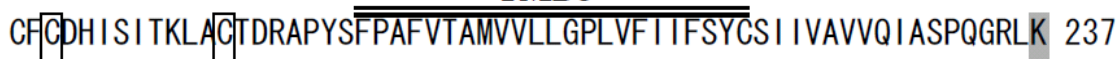
$* Y * * *|*| * \mathrm{~S} * * * \mathrm{TN} * \mathrm{AL} * \mathrm{GV} * * \mathrm{FA}|* \mathrm{MVV} * * \mathrm{GP} * \mathrm{AF} *| * * * \mathrm{CA} * * \mathrm{VA} * \mathrm{~L} \mathrm{HI} \mathrm{S} * \mathrm{TQG} * * * 237$ $* \mathrm{Y} * * *|*| * \mathrm{~S} * * * \mathrm{~T} \mathrm{~N} * \mathrm{AP} * \mathrm{~S}|* * \mathrm{FV} L * \mathrm{MVA} * * \mathrm{TP} * \mathrm{AF} * \mathrm{~V} * * * \mathrm{CA} * \mathrm{~L} \mathrm{LA} * \mathrm{LR}| \mathrm{S} * \mathrm{TQA} * * * 237$ $* \mathrm{f} * * * \mathrm{~V} *|* \mathrm{~T} * * * \mathrm{~T} \mathrm{D} * \mathrm{TL} * \mathrm{GF} * \mathrm{~L} \mathrm{LVN} * \mathrm{~L}| \mathrm{V} * * \mathrm{GS} * \mathrm{~A}|* \mathrm{~V} * * * \mathrm{CA} * * \mathrm{VA} * \mathrm{LR}| \mathrm{S} * \mathrm{AQG} * * * 238$ $* \mathrm{~V} * * * \mathrm{~V} * \mathrm{~V} * \mathrm{~K} * * * \mathrm{I} \mathrm{D} * \mathrm{TP} * \mathrm{AF} * * \mathrm{LVS} * \mathrm{LVM} * * \mathrm{TP} * \mathrm{AF} * \mathrm{~L} * * * \mathrm{GS} * * \mathrm{VT} * \mathrm{FRTS} * \mathrm{TRG} * * * 237$

\section{TMD6}

TMD7

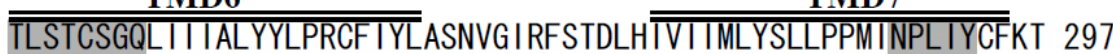

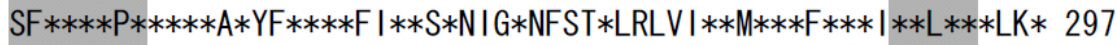
$\mathrm{TF} * * * * \mathrm{P} * * * * * \mathrm{~A} * \mathrm{YF} * * * * \mathrm{~F}|* * \mathrm{~S} * \mathrm{~N}| \mathrm{G} * \mathrm{YFST} * \mathrm{LRLA} \mid * * \mathrm{M} * * * \mathrm{~F} * * * \mathrm{~F} * * \mathrm{~L} \mathrm{~L} * * * \mathrm{LR} * 297$ $\mathrm{TF} * * * * \mathrm{P} * * * * * \mathrm{~A} * \mathrm{FF} * * * * \mathrm{FN} * * \mathrm{~S} * \mathrm{Y}|\mathrm{N} * \mathrm{KFST} * \mathrm{LRLV}| * * \mathrm{M} * * * \mathrm{~L} * * * \mid * * \mathrm{~L} * * * \mathrm{LR} * 298$ TL****S*****T*FF****LN**S*SLG*HINA*IQILV**L***L $* * * \mid * * \mathrm{~V} * * * \mathrm{LR} * 297$

KDMKQTLMKK-FKKSTAP-------------_stop >

KEA*ECLKRSLNRSSFVQFLK INVQVSTLSN〈stop〉 328


Fig. 3

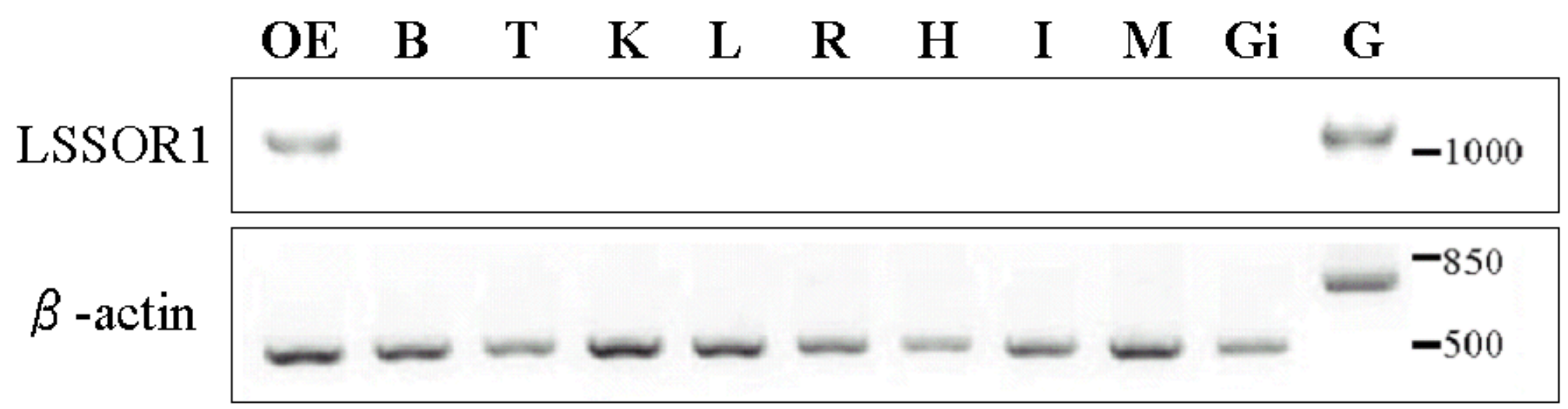




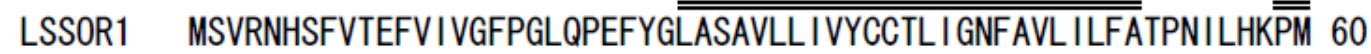
CSOR1 1 S $* * * * * * * * * * * * * \mathrm{~V} * * * * * * * * * * * * * * * * * * \mathrm{~F} * * * \mathrm{~S} * * * * * * \mathrm{~F} * * * * * * * * * * * * * * \mathrm{H} * * * 60$ PSOR1 $\quad * S * * * * * * * * * * * * \mathrm{~V} * * * * * * * * * * * * * * * * * * \mathrm{~L} \mathrm{~L} * * * \mathrm{C} * * * * * * \mathrm{~F} * * * * * * * * * * * * * * \mathrm{H} * * * 60$ MSOR1 $\quad * L$ L*************|*******************L $* * *$ C*******L $* * * * * * * * * * * * * H * * * 60$ RTOR1 $\quad * S * * * * * * * * * * * * \mathrm{~V} * * * * * * * * * * * * * * * * * \mathrm{~L} * * * \mathrm{C} * * * * * * * \mathrm{~F} * * * * * * * * * * * * * 0 * * * 60$

TMD2

TMD3

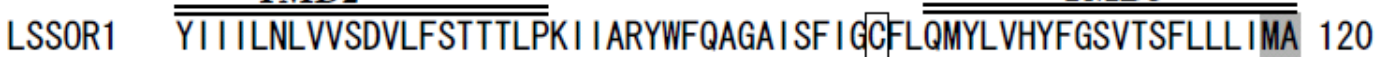
CSOR1 1 1 *************F**************************k*********************** 120

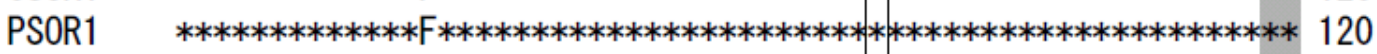
MSOR1 $\quad * * * * * * * * * * * * * \mathrm{~L} * * * * * * * * * * * * * * * * * * * * * * * * * 1 * * * * * * * * * * * * * * * * * * * * * * * * 120$

RTOR1 $\quad * * * * * * * * * * * * * \mathrm{~F} * * * * * * * * * * * * * * * * * * * * * * * * * 1 * * * * * * * * * * * * * * * * * * * * * * * 120$

TMD4

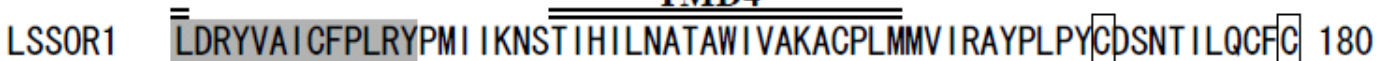
CSOR1 $\quad * * * * * * * * * * * * * * * * * * * * * * * * * * * * * * * * * * * * * * * M * * * * * * * * * * * * * * * * * L * * * * * 180$ PSOR1 $\quad * * * * * * * * * * * * * * * * * * * * * * * * * * * * * * * * * * * * * * * M * * * * * * * * * * * * * * * * * \mathrm{~L} * * * * 180$ MSOR1 $\quad * * * * * * * * * * * * * * * * * * * * * * * * * * * * * * * * * * * * * * * * * * * * M * * * * * * * * * * * k * * * * * * \mathrm{~L} * * * * * 180$

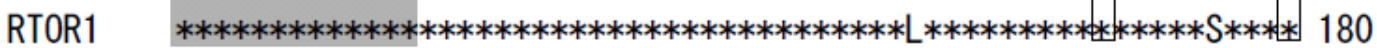

\section{TMD5}

LSSOR1 DHISITKLACTTRAPYSFPAFVTAMVVLLGPLVFIIFSYCSIIVAVVQIASPQGRLK $\overline{\overline{\overline{T L S}}} 240$ CSOR1

PSOR1

MSOR1

RTOR1 *************k************************V***************VQ************* 240

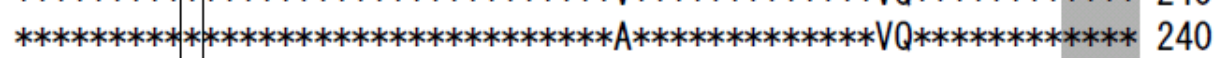

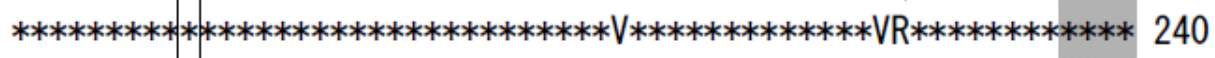

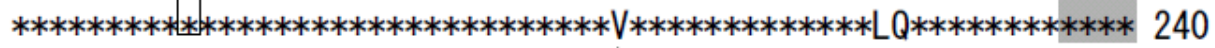

$\boldsymbol{\Delta}$

TMD6

TMD7 


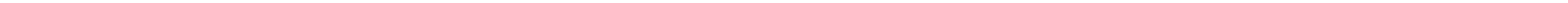

